\title{
Comparison of a supraclavicular block showing upper arm twitching response with a supraclavicular block showing wrist or finger twitching response
}

\author{
Dae Geun Jeon, and Won Il Kim \\ Department of Anesthesiology and Pain Medicine, College of Medicine, Dankook University, Cheonan, Korea
}

Background: Although an ultrasound-guided brachial plexus block has become the standard, conventional brachial plexus blocks with a paresthesia or muscle twitch are still performed. However despite eliciting a paresthesia or muscle twitch, there are some cases in whom the brachial plexus block fails. This has been attributed to the difference between the proximal response (PR) and distal response (DR). Therefore, this study compared a supraclavicular block showing a PR with that showing a DR. In addition, clinical data such as success rate, onset time, and complications were examined.

Methods: Eighty three patients received a supraclavicular block with a nerve stimulator. All blocks were performed with $1 \%$ mepivacaine $40 \mathrm{ml}$. The subjects were divided into two groups- Group PR ( $\mathrm{n}=20$, contraction of triceps or biceps) and Group DR ( $\mathrm{n}=63$, flexion or extension of wrist or fingers) according to the types of muscle twitch. The success rate, onset time, and complications were measured and evaluated.

Results: The success rate of Group DR (93.7\%) was higher than that of Group PR (75.0\%) $(\mathrm{P}<0.05)$. The onset times of Group PR and DR were $15.3 \pm 6.7 \mathrm{~min}$ and $14.4 \pm 6.0 \mathrm{~min}$, respectively.

Conclusions: The elicitation of a DR was more effective in increasing the success rate and reducing the onset time than the elicitation of a PR in a single-injection supraclavicular block. (Korean J Anesthesiol 2010; 58: 464-467)

Key Words: Distal response, Muscle twitch, Proximal response, Supraclavicular block.

Received: February 3, 2010. Revised: 1st, February 22, 2010; 2nd, March 4, 2010. Accepted: March 22, 2010.

Corresponding author: Dae Geun Jeon, M.D., Department of Anesthesiology and Pain Medicine, College of Medicine, Dankook University, Anseo-dong, Cheonan 330-715, Korea. Tel: 82-41-550-6829, Fax: 82-41-551-9330, E-mail: timepain@paran.com

(C) This is an open-access article distributed under the terms of the Creative Commons Attribution Non-Commercial License (http:// creativecommons.org/licenses/by-nc/3.0/), which permits unrestricted non-commercial use, distribution, and reproduction in any medium, provided the original work is properly cited. 


\section{Introduction}

Although real-time ultrasonographic guidance has become the standard of care in a brachial plexus block, many operators still perform the conventional brachial plexus block [1-3].

In the conventional brachial plexus block, the elicitation of a paresthesia or muscle twitch is very important for locating the nerves $[4,5]$. However despite eliciting a paresthesia or muscle twitch, there are some cases in whom the brachial plexus block fails. This has been attributed to the difference between the proximal response (PR) and distal response (DR) of a paresthesia or muscle twitch [6-8]. Borgeat et al. [7] reported that the success rate was higher when a DR was obtained in an infraclavicular block. However it is unclear if this concept can be applied to a supraclavicular block.

Therefore, this study compared a supraclavicular block showing a PR with that showing a DR. In addition, the success rate, onset time, and complications were examined.

\section{Materials and Methods}

After obtaining institutional and ethical committee approval as well as patient consent, eighty three patients with ASA physical status I, II who presented for elective surgery of the forearm and hand were enrolled in this study.

No patients received premedication. Immediately after arriving in the operating room, standard monitoring equipments (EKG, non-invasive blood pressure measurement, pulse oximetry) were attached to all patients before performing the supraclavicular block.

For the supraclavicular block, the patients were placed in the supine position with their heads turned in the direction opposite the limbs to be anesthetized. The arms to be blocked were placed in an anatomical neutral position, along the body. All blocks were performed using a subclavian perivascular approach. After skin preparation, a 22 gauge $5 \mathrm{~cm}$ insulated stimulation needle (B. Braun, Melsungen, Germany) was advanced with a nerve stimulator (Stimulpex ${ }^{\circledR}$, B. Braun, Melsungen, Germany). The placement of the needle was judged

Table 1. Demographic Characteristics of the Patients

\begin{tabular}{lccc}
\hline & Group PR & Group DR & $\begin{array}{c}\text { Total of } \\
\text { Group PR and DR }\end{array}$ \\
\hline Sex (M/F) & $14 / 6$ & $45 / 18$ & $59 / 24$ \\
Age (yr) & $44.6 \pm 14.2$ & $40.3 \pm 14.9$ & $40.7 \pm 14.9$ \\
Height (cm) & $164.4 \pm 6.3$ & $167.2 \pm 7.2$ & $167.1 \pm 27.1$ \\
Weight (kg) & $61.6 \pm 8.8$ & $63.6 \pm 9.5$ & $61.6 \pm 12.5$ \\
\hline
\end{tabular}

The values are reported as the mean \pm SD or the number of patients. Group PR: supraclavicular block with a proximal response, Group DR: supraclavicular block with a distal response. to be successful when a muscle twitch was observed with a threshold intensity $<0.5 \mathrm{~mA}$. $1 \%$ mepivacaine $40 \mathrm{ml}$ was then injected when a muscle twitch was elicited.

The patients were divided into two groups according to the types of muscle twitch responses - a proximal response (PR) and distal response (DR). Contraction of the biceps, triceps, flexor carpi radialis or flexor carpi ulnaris was considered to be a proximal response, and the flexion or extension of the wrist or fingers was considered to be a distal response.

The appearance of the sensory block was checked with a 26 gauge needle. It was evaluated every $5 \mathrm{~min}$ in all 5 nerve territories of the forearm (median nerve, radial nerve, ulnar nerve, musculocutaneous nerve, and medial cutaneous nerve) up to 30 minutes after injecting the local anesthetic. A successful block was defined as a complete sensory block of all 5 nerves of the forearm within 30 minutes of the local anesthetic injection and operability. The average onset time of each nerve was obtained from the patients with a successful block.

Only sedation with intravenous midazolam and propofol infusion was performed if the territory that was not anesthetized was not a surgical area. However, an axillary block or general anesthesia was done if any potentially surgical territory was not completely anesthetized at 30 minutes after the block.

The data was analyzed using a Student t-test, Mann-Whitney $\mathrm{U}$ test, and Chi-square test. A P $<0.05$ was considered significant.

\section{Results}

Eighty three patients were included in this study. There were no differences in the characteristics between the 2 groups (Table 1). A PR and a DR were elicited in 20 patients (Group PR) and 63 patients (Group DR), respectively.

The success rate of Group DR (93.7\%) was higher than that of Group PR $(75.0 \%)(\mathrm{P}<0.05)$ and the overall success rate was 90.3\% (Table 2). There were 5 failures in Group PR and 4 failures in Group DR. In Group PR, 1 failure received sedation only, 3 failures received an axillary block and 1 failure received general

Table 2. Extension of Anesthesia in Patients with a Proximal or a Distal Response to Nerve Stimulation

\begin{tabular}{lcc}
\hline \multicolumn{1}{c}{ Sensory territory } & $\begin{array}{c}\text { Success rate of } \\
\text { Group PR (\%) }\end{array}$ & $\begin{array}{c}\text { Success rate of } \\
\text { Group DR (\%) }\end{array}$ \\
\hline All 5 nerves & 75.0 & $93.7^{*}$ \\
Median nerve & 95.0 & 96.8 \\
Ulnar nerve & 75.0 & $95.2^{*}$ \\
Radial nerve & 95.0 & 96.8 \\
Musculocutaneous nerve & 95.0 & 96.8 \\
Median cutaneous nerve & 85.0 & $96.8^{*}$ \\
\hline
\end{tabular}

Group PR: supraclavicular block with a proximal response, Group DR: supraclavicular block with a distal response. $* \mathrm{P}<0.05$ compared with Group PR. 
Table 3. Demographic Characteristics of the Patients with an Unsuccessful Block

\begin{tabular}{|c|c|c|c|c|c|c|}
\hline $\begin{array}{l}\text { Patients with } \\
\text { failed block }\end{array}$ & Sex & $\begin{array}{l}\text { Age } \\
(\mathrm{yr})\end{array}$ & $\begin{array}{l}\text { Height } \\
(\mathrm{cm})\end{array}$ & $\begin{array}{l}\text { Weight } \\
(\mathrm{kg})\end{array}$ & Spared nerve & Supplementation \\
\hline PR1 & $\mathrm{M}$ & 36 & 173 & 75 & Ulnar & Sedation only \\
\hline PR2 & $\mathrm{F}$ & 41 & 161 & 64 & Ulnar & Axillary block \\
\hline PR3 & $\mathrm{M}$ & 50 & 158 & 62 & Ulnar, Md.c & Axillary block \\
\hline PR4 & $\mathrm{M}$ & 39 & 170 & 64 & All five nerves & General anesthesia \\
\hline PR5 & $\mathrm{F}$ & 51 & 156 & 47 & Ulnar, Md.c & Axillary block \\
\hline DR1 & $\mathrm{F}$ & 45 & 160 & 70 & Ulnar & Axillary block \\
\hline DR2 & M & 52 & 175 & 58 & Median, radial, Mc & General anesthesia \\
\hline DR3 & $\mathrm{F}$ & 61 & 153 & 65 & Ulnar, Md.c & Axillary block \\
\hline DR4 & M & 57 & 176 & 75 & All five nerves & General anesthesia \\
\hline
\end{tabular}

PR: patient in Group PR (supraclavicular block with a proximal response), DR: patient in Group DR (supraclavicular block with a distal response), M: male, F: female, Md.c: medial cutaneous nerve, Mc: Musculocutaneous nerve.

Table 4. Time to the Onset of Each of the 5 Terminal Nerves

\begin{tabular}{lrrr}
\hline \multirow{2}{*}{ Sensory distribution } & \multicolumn{3}{c}{ Time to onset (minutes) } \\
\cline { 2 - 4 } & Group PR & Group DR & $\begin{array}{c}\text { Average of } \\
\text { Group PR and DR }\end{array}$ \\
\hline Musculocutaneous nerve & $8.7 \pm 3.5$ & $10.3 \pm 4.8$ & $9.9 \pm 4.5$ \\
Radial nerve & $9.7 \pm 5.2$ & $8.0 \pm 4.4$ & $8.4 \pm 4.5$ \\
Ulna nerve & $12.7 \pm 8.4$ & $10.4 \pm 6.3$ & $10.9 \pm 6.7$ \\
Median nerve & $10.0 \pm 6.3$ & $9.8 \pm 5.7$ & $9.8 \pm 5.7$ \\
Median cutaneous nerve & $8.7 \pm 3.5$ & $9.8 \pm 5.7$ & $9.6 \pm 5.3$ \\
Average of all nerves & $15.3 \pm 6.7$ & $14.4 \pm 6.0$ & $14.6 \pm 6.1$ \\
\hline
\end{tabular}

The values are reported as the mean \pm SD. Group PR: supraclavicular block with a proximal response, Group DR: supraclavicular block with a distal response.

anesthesia. In Group DR, 2 failures received an axillary block and another 2 failures received general anesthesia (Table 3 ).

The onset time of Group PR and DR were $15.3 \pm 6.7 \mathrm{~min}$ and $14.4 \pm 6.0 \mathrm{~min}$, respectively. The onset time of Group DR was shorter than that of Group PR, but the difference was not statistically significant (Table 4).

The orders of onset time were as follows: 1) musculocutaneous nerve 2) medial cutaneous nerve 3) radial nerve 4) median nerve 5) ulnar nerve in Group PR, and 1) radial nerve 2) median nerve 3) medial cutaneous nerve 4) ulnar nerve 5) musculocutaneous nerve in Group DR. However, there was no statistically significance despite their order.

There were no complications such as pneumothorax or neurological injury.

\section{Discussion}

The success rate of a supraclavicular block with a DR was higher than that of a supraclavicular block with a PR in our study. Understanding why requires detailed knowledge of the anatomy of brachial plexus.

The brachial plexus is derived from the fifth, sixth, seventh, and eighth cervical nerves and the first thoracic nerve. The nerves form trunks between the anterior and middle scalene muscles, and descend down to the clavicle and first rib. As the trunks pass between the clavicle and first rib, each trunk divides into anterior and posterior divisions. A supraclavicular block is performed at the first rib level in this region. Anatomical arrangement of the fibers in the trunks of the brachial plexus shows that fibers in the center of the bundle innervate the distal arm $[7,9,10]$. This concept may explain why the success rate is higher in supraclavicular block that elicits a distal response.

Therefore, to improve the success rate of supraclavicular block, the operator should place the needle into the center of the brachial plexus bundle. It is important to know the precise needle location without a real time image, such as ultrasound. Traditionally, the elicitation of paresthesia or a muscle twitch with a nerve stimulator allows for a precise needle location. Therefore, higher success rate depends on understanding the relationship between the nerves and paresthesia (or a muscle twitch).

In the case of nerve localization with paresthesia, the operator can obtain information on the needle position with the following locations of paresthesia: 1) lateral side of the forearm (musculocutaneous nerve); 2) medial side of the forearm (medial cutaneous nerve); 3) lateral side of the hand and thumb, second and third finger (median nerve); 4) medial side of the palm and the dorsum of the hand, and the fourth and fifth finger (ulnar nerve); and 5) lateral side of the dorsum of the hand (radial nerve) $[2,5,11,12]$.

On the other hand, for nerve localization with a muscle twitch, it is important to understand that each muscle twitch response is related to the stimulation of different nerves: 1) shoulder abduction (supraclavicular nerve, suprascapular nerve and axillary nerve); 2) elbow flexion (musculocutaneous nerve); 3) elbow extension (radial nerve); 4) wrist flexion (median nerve); 5) wrist extension (radial nerve); 6) flexion of the thumb, the second and the third finger (median nerve); 7) flexion of the fourth and the fifth finger (ulnar nerve); 8) thumb abduction 
(radial nerve); and 9) thumb adduction (ulnar nerve) [2,5,11,12].

In Bogeat et al.'s study, the success rates were $97 \%$ when a distal response was elicited, and $44 \%$ when a proximal response was observed in infraclavicular block. In the present study, the successes rates were $93.7 \%$ and $75.0 \%$ when a distal response and proximal response were noted, respectively [7]. Our success rate of a proximal response was much higher (75\% vs $44 \%$ ) than that reported by Bogeat et al. There are some possible explanations for this. First, the brachial plexus is more compact in the supraclavicular region than in the infraclavicular region. The local anesthetic injected in periphery of the brachial plexus (when elicited a proximal response) spread into the center of the brachial plexus much easier than that in the infraclavicular block. Second, in the supraclavicular region, there are more nerve interconnections than in the infraclavicular region.

It was also observed that the orders of onset time were different between the two groups. The onset time of musculocutaneous nerve anesthesia was the shortest in Group PR, whereas the onset time of radial nerve anesthesia was the shortest in Group DR. These results suggest that the reason for the difference was the needle location. In Group PR, the needle was placed near the musculcoutaneous nerve, and the local anesthetic reached the musculocutaneous nerve first. In contrast, the needle was near the radial nerve in Group DR, and the local anesthetic spread the radial nerve first.

We acknowledge that this study has several limitations. The most important limitation to this study is that PR and DR were not provoked intentionally. Therefore, the differences between groups may be the differences between each individual's constitution. i.e. the patients in Group PR may have some difficulties in being anesthetized. Before this study, there were plans to provoke PR and DR intentionally. However this was not done due to the fear of causing discomfort to the patients. Another limitation was that a single anesthesiologist performed all the blocks. Although it may eliminate interoperator variability, it may limit the generality of the results.

In conclusion, the elicitation of a distal response was more effective in increasing the success rate and reducing the onset time than the elicitation of a proximal response in a singleinjection supraclavicular block.

\section{References}

1. Chan VWS, Perlas A, Rawson R, Odukoya O. Ultrasound-guided supraclavicular brachial plexus block. Anesth Analg 2003; 97: 1514-7.

2. Kapral S, Krafft P, Eibenberger K, Fitzgerald R, Gosch M, Weinstabl C. Ultrasound-guided supraclavicular approach for regional anesthesia of the brachial plexus. Anesth Analg 1994; 78: 507-13.

3. Perlas A, Lobo G, Lo N, Brull R, Chan VWS, Karkhanis R. Ultrasoundguided supraclavicular block: outcome of 510 consecutive cases. Reg Anesth Pain Med 2009; 34: 171-6.

4. Choyce A, Chan VWS, Middleton WJ, Knight PR, Peng P, McCarteny CJL. What is the relationship between paresthesia and nerve stimulation for axiallary brachial plexus block? Reg Anesth Pain Med 2001; 26: 100-4.

5. Fanelli G, Casati A, Garancini P, Torri G. Nerve stimulator and multiple injection technique for upper and lower limb blockade: failure rate, patient acceptance, and neurologic complications. Anesth Analg 1999; 88: 847-52.

6. Fitzgibbon DR, Debs AD, Erjavec MK. Selective musculocutaneous nerve block and infraclavicular brachial plexus anesthesia. Reg Anesth 1995; 20: 239-41.

7. Bogeat A, Ekatodramis G, Dumont C. An evaluation of the infraclavicular block via a modified approach of the Raj technique. Anesth Analg 2001; 93: 436-41.

8. Rodriguez J, Taboada-Muiz M, Barcena M, Alvarez J. Median versus musculocutaneous nerve response with single-injection infraclavicular coracoid block. Reg Anesth Pain Med 2004; 29: 534-8.

9. Wedel DJ, Horlokcer TT. Nerve blocks. In: Miller's Anesthesia. 7th ed. Edited by Miller RD: Philadelphia, Churchill Living Stone. 2010, p 1640 .

10. Morgan GE, Mikhail MS, Murray MJ. Clinical Anesthesiology. 4th ed. New York, Lange Medical Books/McGraw-Hill Medical Publishing Division. 2006, pp 329-3.

11. Neal JM, Moore JM, Kopacz DJ, Liu SS, Kramer DJ, Plorde JJ. Quantitative analysis of respiratory, motor, and sensory function after supraclavicular block. Anesth Analg 1998; 86: 1239-44.

12. O'Donnell BD, Iohom G. An estimation of the minimum effective anesthetic volume of $2 \%$ lidocaine in ultrasound-guided axillary brachial plexus block. Anesthesiology 2009; 111: 25-9. 